\title{
Improvements through the Second Year Research Experiences for Teachers Program
}

\section{Prof. Tolga Kaya, Central Michigan University}

Dr. Tolga Kaya currently holds a joint Assistant Professor position in the School of Engineering and Technology and the Science of Advanced Materials program at Central Michigan University (CMU). Prior to joining CMU, Dr. Kaya was a post-doctorate associate at Yale University (2007-2010), a research and teaching assistant at ITU (1999-2007), a consultant at Brightwell Corp. (2007), Istanbul, a senior VLSI analog design engineer and project coordinator at Microelectronics R\&D Company, Istanbul (2000-2006), and a visiting assistant in research at Yale University (2004-2005). Dr. Tolga Kaya received BS, MS and $\mathrm{PhD}$ degrees in Electronics Engineering from Istanbul Technical University (ITU), Istanbul, Turkey. His research interests in electrical engineering and applied sciences are analog VLSI circuit design, MEMS sensors and energy harvesting systems. His research is also involved in biomedical engineering where bacterial hydrodynamics are studied under various shear flow regimes to enlighten the bacterial infections in catheterized patients. Dr. Kaya also works on engineering education, particularly STEM relationships with K-12 and active learning techniques. 


\title{
Improvements through the Second Year Research Experiences for
}

\section{Teachers Program}

\begin{abstract}
We have successfully finished our second summer in our National Science Foundation (NSF) supported Research Experiences for Teachers (RET) Site entitled "Multidisciplinary Engineering Research for Rural Michigan's Future." The summer program was 6 weeks long and hosted 7 inservice teachers (high school science) and 5 pre-service teachers (integrated science majors). Participants were split into 6 groups and teamed up with an engineering faculty and an engineering undergraduate student each. During their 40 hours/week work schedule, participants worked on faculty supervised research projects for half their time, and the rest was reserved for classroom unit plans that participants would work on developing. Different from the first year, participants were assigned management roles during the summer. Also, each participant prepared new lesson plans and classroom activities that align with the Next Generation Science Standards (NGSS). The academic year class activities from first year were debriefed and learned lessons were generated. In this paper, we will give the details about the RET Site's management and discuss our experiences from our second year with the improvements and their effects. We hope that our shared experiences (struggles, accomplishments, mistakes, etc.) will help the engineering education community develop more effective relationships with K-12 by using the models we implemented.
\end{abstract}

\section{Introduction}

As engineering becomes one of the target fields for high school education to focus, the National Science Foundation's (NSF) Research Experiences for Teachers (RET) program is found to be timely and very important. The program seeks collaborations between universities and K-12 educators with hopes to create partnerships in the future. This unique opportunity will clearly shorten the gap between the college and high school education system. We were granted to conduct a 3-year RET program. This program allows us to bring 12 in- or pre-service teachers during the summer to conduct engineering research and work on the applications of the gained knowledge to teachers' classrooms. The 6-week long summer program is followed by classroom visits. 


\section{RET Site Management}

As NSF encourages RET sites to have the same participants for consecutive years, we have only advertised the program for two spots of those absent for personal reasons of those participants. Last year, we had 7 in-service and 5 pre-service teachers. This year, we were able to include another pre-service teacher but we remained the same numbers in terms of participants because one of our last year's pre-service teachers graduated and started as an in-service teacher.

Different from last year, we have set the expectations clearly. A document was prepared and sent it to our participants in advance by stating the following expectations and deliverables:

- Each participant will prepare lesson plans and/or classroom activities and present those to us (some of you will have particular assignments in this expectation). We call this TDL (Teaching a Developed Lesson). Expect to present one or two TDLs.

- Last year's in-service teachers will give a 1-2 hour lesson that they have changed/modified last year according to their experience from last summer. We call this TCL (Teaching a Changed Lesson).

- Each participant will write a report of potential applications/ties of the research to their teaching.

- Each participant will prepare a poster for the final day of the program.

We also assigned some specific roles for each participant to self-manage some of the administrative duties that are given below:

Technologist: XX will organize some education technology workshops. He will also maintain the web site and supervise those who have technology implementation component in their lesson plans.

TD bugger/supervisor: XX will be overseeing all TD (Teacher development) projects may it be a lesson plan or classroom activity development. She will "bug" you often to make sure you are in the right track in terms of RET program goals.

Vernier guru: XX will organize some workshops on Vernier probes. He will also help others implement Vernier related activities.

Luncher: We will have lunch gatherings three times a week. XX will be responsible facilitating the conversations with visitors. This might include setting the initial theme or steering the conversation to the direction that fits to everybody. 
Digitizers: XX and YY will develop the entire EGR 190 (Digital Circuits) class content and related activities. This class that $\mathrm{ZZ}$ taught last year will be completely flipped!

Reporter: XX will keep the blog updates, take pictures during TD and research, and ask questions, work on the Facebook page and Twitter.

Activists: This year's academic year visits will be planned and developed during the program. XX will lead this effort. YY, ZZ, and TT will develop the activities.

Forumist: XX will organize forums about describing, evaluating, and comparing professional training among participants.

NGSSers: We need to make sure that your TD time aligns well with NGSS. Therefore, XX and YY will make extra effort to check all the developed material addresses a related content in NGSS.

The daily agenda of the program was slightly changed to keep every day consistent. The following schedule was distributed to the participants:

8.30 am -9 am: Breakfast

9 am - 12 pm: TD (Teaching development)

12 pm - 1 pm: Working lunch (M, W, F)

1 pm - 5 pm: Research

Different from last year, the classroom activities were developed during the summer program and most of the activities have been implemented in the classrooms of the in-service teachers already.

A comprehensive assessment plan was developed and participants were surveyed at the beginning and the end of the program. While we are still in the process of analyzing the data, the questions for the surveys were listed below: 


\section{Participant End-of-Summer Program Questionnaire}

1. What is your name? (Note: This is for tracking purposes only; your name will be replaced with a random number.)

PART ONE: PROGRAM OBJECTIVES:

This summer program has been designed with specific objectives in mind. For Items 2-7, please rate each of the objectives according to your perception of whether you think the objective was ACCOMPLISHED. A " 1 " on the scale represents a "low" level of accomplishment; a " 5 " represents a "high" level of accomplishment. Please make comments.

2. Foster trusting, successful working relationships between faculty researchers, experienced engineering students, and teachers.

3. Develop skills, abilities, and attitudes related to leadership, curriculum development, and assessment.

4. Facilitate the development of high school STEM-based classroom instructional materials for use in rural areas of northern Lower Michigan.

5. Convey basic engineering concepts through research projects on smart vehicles.

6. Successfully implement a six-week summer research experience within the School of Engineering and Technology (SET) labs at CMU.

7. Recognize "scientific language" and "teacher language," and know when and how to use each language.

SECTION TWO: PROGRAM ACTIVITIES:

For Items 8-14, please rate the various summer program activities on their usefulness on a scale of 1-5, with $1=$ Not useful and $5=$ Very Useful. Please make comments.

8. Participating in intensive research on various aspects of smart car vehicle development.

9. Coaching on curriculum development with new standards.

10. CMU faculty visits highlighting research and education topics.

11. Training sessions for lab instruments and/or tools.

12. Professional development sessions on effective teaching.

13. Social activities and team building activities.

14. Reflection sessions.

SECTION THREE: RESEARCH

For Items 15-19, rate each statement on a scale of 1-5, with $1=$ Strongly Disagree and $5=$ Strongly Agree. Please make comments.

15. Expectations of the summer program were clearly communicated from the start.

16. Program staff kept me informed of program activities (e.g., the schedule was clearly communicated).

17. My responsibilities in the research lab were clearly explained.

18. The faculty leader of my research team was readily available to answer my questions.

19. A collaborative and helpful tone was established during the summer program.

SECTION FOUR: FUTURE PLANS

20. Are you planning to participate in a scientific conference? ___ Yes ___ No If yes, please describe:

21. Are you planning to develop a poster or research paper of your work? __ Yes _ _ No If yes,

please describe:

22. Are you planning to make any formal presentations of your work? ___ Yes __ No If yes, please describe:

23. Do you have plans for graduate school? __ Yes __ No If so, what are those plans?

PART FIVE: PERCEPTIONS OF ENGINEERING DISCIPLINE

For Questions 24-33, rate the degree to which you agree or disagree with each statement on a 5point scale, with $1=$ strongly disagree to $5=$ strongly agree. Please make comments to explain your ratings. 
24. You have to study engineering for a long time before you see how useful it is.

25. Memorization plays a central role in learning basic science and engineering concepts.

26. A lot of things in science must be simply accepted as true and remembered.

27. It is important to teach students how to think and communicate scientifically.

28. Every student should feel that science is something she/he can do.

29. Every student should feel that engineering is something she/he can do.

30. I understand science concepts well enough to be effective in teaching them.

31. I understand engineering concepts well enough to be effective in teaching them.

32. I am typically able to answer students' questions related to science.

33. I am typically able to answer students' questions related to engineering.

PART SIX: NEXT GENERATION SCIENCE STANDARDS

34. Rate the degree to which you are familiar with the Next Generation Science Standards (NGSS) on a

5 -point scale, with $1=$ no familiarity to $5=$ very familiar. Please make comments to explain your ratings.

35. Please make three to five statements which reflect specific terms or ideas that you recall about the

Next Generation Science Standards (NGSS).

SECTION SEVEN: REFLECTIONS

For Questions 36-41, rate the degree to which you agree or disagree with each statement on a 5point scale, with $1=$ strongly disagree to $5=$ strongly agree. Please make comments to explain your ratings.

36. I plan to develop or modify lesson plans or classroom activities this academic year that are aligned with NGSS or general engineering.

37. I was actively involved in an engineering research project with focus on smart-vehicles.

38. The activities that I engaged in this summer continually built on what I learned and lead to more advanced work.

39. I found it useful/helpful to work with an in-service/pre-service teacher.

40. I found it useful/helpful to work with an undergraduate student.

41. I found it useful/helpful to work with an engineering faculty.

42. Please describe at least one or two ways that you will use what you have learned or developed through the summer program.

43. What are one or two BIG things that you have learned through your participation in the summer program?

44. How could the summer program have been improved?

45. Did the program meet your expectations in delivering what you were looking for? _ Yes ___ No.

Please explain why or why not.

46. What were the main challenges in the program? Were they any different than what you initially anticipated?

47. After participation in this program, did your perception on benefits to high school students change? If so, how?

48. Is there anything else that you would like to say?

\section{Interview Questions for Program Participants}

QUESTIONS FOR TEACHER AND ENGINEERIN G STUDENT TEAM MEMBERS:

1. (All) What is your role in this project?

2. (All) Why did you decide to participate in this project?

3. (All) Please describe the activities that you and your research team engaged in.

4. (All) How would you describe your working relationship with your faculty research team leader?

With other members of your team? In what ways would you like to see these working relationships 
change?

5. (All) In what way has your knowledge of engineering/science been enhanced by participating in this program? Be specific.

6. (All) A central activity of each research team was a weekly group meeting focused on the progress of the group in terms of both its own internal functioning and its research analysis and implementation. Did you find these meetings beneficial? Why or why not?

7. (Teachers only) In what way do you think your students will benefit from your participation in this program?

8. (Teachers only) Would you recommend to one of your teacher colleagues that they participate in the program? Why or why not?

9. (Engineering students only) How have you benefitted from participating in the CMU-RET program? What have you learned? How have your skills improved?

10. (All) What are the strengths of the CMU-RET program?

11. (All) What are the limitations of the program?

12. (All) What suggestions do you have for improving the program?

13. (All) Is there anything else that you would like to say about the program or about your experiences with it?

\section{Conclusion}

We believe we had a very successful second year from our RET program. We were able to engage the participants more by assigning some roles for them. Our research projects were also defined better than the first year so participants benefited more since they were able to understand what they were required to do from the very beginning. We hope to improve our program by analyzing the survey results and discussing with next year's participants. 